\title{
Compulsory community service for doctors in South Africa:
} \section{A 15-year review} \author{
G Wolvaardt, ${ }^{3} \mathrm{MB} \mathrm{ChB}, \mathrm{MMed}, \mathrm{FCP}(\mathrm{SA})$ \\ ${ }^{1}$ Primary Health Care Directorate, Faculty of Health Sciences, University of Cape Town, South Africa \\ ${ }^{2}$ Africa Health Placements, Johannesburg, South Africa \\ ${ }^{3}$ Foundation for Professional Development, Pretoria, South Africa
}

S J Reid, ${ }^{1}$ MB ChB, MFamMed, PhD; J Peacocke, ${ }^{2}$ BSc (Med), MSc (Med); S Kornik, ${ }^{2}$ BBusSci, BComm Hons, MCom, CA (SA);

Corresponding author: S J Reid (steve.reid@uct.ac.za)

\begin{abstract}
Background. Compulsory community service (CS) for health professionals for 12 months was introduced in South Africa (SA) in 1998, starting with medical practitioners. Up to 2014, a total of 17413 newly qualified doctors and $\sim 4000$ health professionals had completed their year of service in public health facilities around the country. While a number of studies have described the experience and effects of CS qualitatively, none has looked at the programme longitudinally.

Objectives. To describe the findings and analyse trends from surveys of CS doctors between 2000 and 2014, specifically with regard to their distribution, support, feedback and career plans.

Methods. A consecutive cross-sectional descriptive study design was used based on annual national surveys of CS doctors. The study population of between 1000 and 1300 each year was surveyed with regard to their origins, allocations, experiences of the year and future career plans.

Results. The total study population varied between 1057 and 1308 each year, with response rates of $20-77 \%$. The average turn-up rate of $89 \%$ showed a decreasing tendency, while $77 \%$ of respondents were satisfied with the allocation process. Over the 15-year period, the proportion of CS doctors who were black and received a study bursary, and who were allocated to rural areas and district hospitals, increased. The great majority believed that they had made a difference (91\%) and developed professionally (81\%) over the course of the year, but only about half felt adequately supported clinically and administratively. The attitude towards CS of the majority of respondents shifted significantly from neutral to positive over the course of the 15 years. In terms of future career plans, $50 \%$ hoped to specialise, a decreasing minority to go overseas or into private practice, and a constant $15 \%$ to work in rural or underserved areas.

Conclusions. This study is the first to track the experience of compulsory CS over time in any country in order to describe the trends once it had become institutionalised. The SA experience of CS for doctors over the first 15 years appears to have been a successively positive one, and it has largely met its original objectives of redistribution of health professionals and professional development. Greater attention needs to be given to orientation, management support and clinical supervision, and focusing professional development opportunities on the important minority who are prepared to stay on longer than their obligatory year. CS still needs to be complemented by other interventions to capitalise on its potential.
\end{abstract}

S Afr Med J 2018;108(9):741-747. DOI:10.7196/SAMJ.2018.v108i9.13070

Since the implementation in 1998 of the community service (CS) programme for 12 months of compulsory service for health professionals up to and including 2014, a total of 17413 doctors of $\sim 44000$ CS health professionals completed their year of service in public health facilities in South Africa (SA) ${ }^{[1]}$ Doctors were the first to be contracted under this programme, followed by dentists, pharmacists and eventually all other health professionals, including nurses, who form the largest cohort. ${ }^{[2]}$ The scheme currently employs an annual cohort of $\sim 8000$ young professionals on 12-month contracts, who are allocated to public health facilities in different provinces according to the human resources need. While a number of studies have described the initial experience and effects of CS officers of various professional groups qualitatively, ${ }^{[3-7]}$ none has yet looked at the programme longitudinally. This article focuses on medical practitioners, about whom most of the longitudinal data have been accumulated based on an annual survey of CS officers that was instituted in $2000 .{ }^{[3]}$

CS in SA primarily aimed to improve the supply of professional health personnel in underserved areas, thereby improving health service provision to all South Africans. ${ }^{[3]}$ The objectives, gathered from a speech by Dr Ayanda Ntsaluba, director general of health in 1998, were as follows:
- to ensure improved provision of health services to all citizens of the country

- to provide our young professionals with an opportunity to further develop their skills, acquire knowledge and develop behaviour patterns and critical thinking that would help them in their professional development and future careers.

It is significant that the two objectives appear to be given equal importance, although the former might be regarded as the main purpose of the CS year. However, as the programme was said to be 'service, not training, CS officers were allocated according to healthcare needs, as determined by the National Department of Health, ${ }^{[4]}$ rather than according to available supervision. ${ }^{[3]}$

Frehywot et al., ${ }^{[9]}$ in their study of compulsory service programmes worldwide, found that SA is one of 70 countries globally that implements compulsory CS. ${ }^{[9]}$ They described three different types of compulsory service in different countries as follows:

- a condition of service/state employment programme, e.g. for foreignqualified professionals

- compulsory service with incentives, such as education, employment or living conditions

- compulsory service without incentives. 
SA falls into the second category, with CS as a requirement for attaining full registration to practise publically or privately. A second strategy in the same category, which operates in countries such as Pakistan and Peru, uses a period of service in an underserved area as a prerequisite for career advancement such as specialisation. No rigorous study has systematically compared countries with rural and remote workforce disparities with compulsory service with those that do not have such programmes. They concluded that compulsory service programmes are a mechanism for staffing and reinforcing the health workforce, especially in areas where access to primary and essential healthcare services and systems are weak, but this should not be the only mechanism.

In 2010 the World Health Organization (WHO) developed a comprehensive set of guidelines based on the best available evidence for the recruitment and retention of healthcare professionals in rural and remote areas (Table 1), which include 'regulatory' interventions, such as compulsory service. ${ }^{[10]}$ This places the strategy of coercion into a broader set of options for increasing the supply of health professionals in areas that are difficult to staff. ${ }^{[1]}$

In light of these alternatives, it is important to analyse the implementation and subsequent effect of the CS programme in SA against the initial objectives. Since its launch in 1998, various evaluations of the CS programme in SA have been completed, most of them qualitative in nature, focusing on its effectiveness, ${ }^{[12-15]}$ to the extent of calling for its revision. ${ }^{[16]}$ An analysis of the first year of CS implementation, using mixed methods, revealed a situation of some confusion in the absence of more specific guidelines. Consequently, provinces were left to make their own rules, which resulted in very variable implementation. ${ }^{[3]}$ This initial study developed the first version of a survey tool, which was subsequently used annually until 2015, with some modifications, and forms the basis of the current review. Although the survey instrument has been modified over the intervening years, a sufficient number of data elements has remained unchanged to allow longitudinal trends to be described and comparisons made between the outcomes and demographic information, placement sites, provinces and universities of graduation.

Using the same data, a detailed study of the 2009 cohort of CS doctors developed a supervision satisfaction score (SSS) and found a high level of participant satisfaction with CS. ${ }^{[17]}$ The authors noted that participants reporting professional development during the CS year were twice as likely to report intentions to remain in rural, underserved communities.

The initial 2001 study called for the establishment of a 'comprehensive policy of human resources for medically underserved areas in South Africa, with obligatory CS for doctors constituting only a part of it. ${ }^{\left[{ }^{[3]}\right.}$ It is in this context that the National Department of Health eventually developed a Human Resources for Health (HRH) strategy in 2011, ${ }^{[18]}$ which included three strategic objectives directly relevant to CS: human resource management, quality of care and access in rural areas (Table 2).

By the time that the HRH strategy for 2012/2013 - 2016/2017 was published in 2011, the CS programme had already been running for 13 years and was institutionalised; therefore, the complementary strategies of the broader HRH policy framework that needed to optimise CS were not implemented for most of the period studied.

A summit on CS, convened by the Foundation for Professional Development (FPD) in 2015, aimed to review the progress of the programme and make recommendations for its further development. ${ }^{[19]}$ Some of the results reported in this article were reported then, and the recommendations arising from the summit workshop have been

Table 1. Categories of interventions used to improve attraction, recruitment and retention of health workers in remote and rural areas ${ }^{[10]}$

\begin{tabular}{ll}
\hline Categories of intervention & Examples \\
\hline A. Educational interventions & Recruit students from rural background \\
& Health professional schools outside of major cities \\
& Clinical rotations in rural areas during studies \\
& Curricula that reflect rural health issues \\
& Continuous professional development for rural health workers \\
B. Regulatory interventions & Enhanced scope of practice \\
& Different types of health workers \\
& Compulsory service \\
C. Financial incentives & Subsidised education for return of service \\
D. Professional and personal support & Appropriate financial incentives \\
& Better living conditions \\
& Safe and supportive working environment \\
& Outreach support \\
& Career development programmes \\
& Public recognition measures
\end{tabular}

Table 2. Strategic objectives of the national HRH strategy relevant to $\mathrm{CS}^{[18]}$

\begin{tabular}{|c|c|c|}
\hline Strategic objective 6 & Strategic objective 7 & Strategic objective 8 \\
\hline Professional human resource management & Quality professional care & Access in rural and remote areas \\
\hline $\begin{array}{l}\text { To effectively manage human resources in a } \\
\text { manner that attracts, retains and motivates the } \\
\text { health workforce to both the public and private }\end{array}$ & $\begin{array}{l}\text { To develop a health workforce that delivers an } \\
\text { evidence-based quality service, with competence, } \\
\text { care and compassion }\end{array}$ & $\begin{array}{l}\text { To promote access to health } \\
\text { professionals in rural and remote areas }\end{array}$ \\
\hline
\end{tabular}

$\mathrm{HRH}=$ Human Resources for Health; $\mathrm{CS}=$ community service; $\mathrm{NDoH}=$ National Department of Health 
incorporated into this article, representing the collective proposals of stakeholders rather than those of the authors alone.

\section{Methods}

\section{Study objectives}

This project aims to describe findings and analyse trends from surveys of CS doctors in SA between 2000 and 2014, specifically with regard to their distribution, support, feedback and career plans.

\section{Study design}

A consecutive cross-sectional descriptive study design was used based on annual national surveys of CS doctors.

\section{Study variables}

A structured self-assessment questionnaire developed from initial qualitative research conducted in $2000^{[3]}$ was used, with some changes, adjustments and additions throughout the period. Most items requiring a subjective response were presented in the form of a 5-point Likert scale. Demographic variables included gender, race, marital status and receipt of a provincial bursary. Medical training characteristics included the university attended and level of the hospital of internship. A number of items explored characteristics of CS placement, including whether the facility was the participant's first, second or third choice in the allocation process. Rural placement was determined by participants, who indicated whether they received a government rural allowance. Placement satisfaction included practical items such as quality of accommodation, overtime duties, personal safety, fairness of remuneration and timeous payment of salaries. Their experiences of CS were indicated, e.g. by questions related to their attitude to CS, professional development, supervision and availability of seniors. Future career plans were assessed in terms of their intention to work in the public service or private sector, to specialise, or to work overseas or in a rural or underserved community.

\section{Data collection}

National, cross-sectional data were collected from CS officers using the abovementioned survey tool administered in the final quarter of each respective year. The cross-sectional design and methodology for the study from 2000 to 2008 made use of hard copies of the survey forms distributed and collected via provincial and hospital CS co-ordinators throughout SA. Attention was paid to confidentiality by using sealed envelopes when the hard-copy questionnaires were collected by the hospital CS co-ordinators. For the 2009 and subsequent studies, in an attempt to improve the response rate and validity, the methodology was according to that performed by Hatcher et al., ${ }^{[17]}$ in which participants were invited to complete the same survey instrument online, supplemented by follow-up phone calls to non-respondents, collated by an independent non-governmental organisation, Africa Health Placements. An information sheet explaining the study stipulated that completion of the survey implied consent, and that the survey was anonymous.

Additional information regarding turn-up rates was obtained directly from the National Department of Health. Turn-up rates were defined as the proportion of doctors who took up CS posts after completing their internship.

\section{Data analysis}

Data were cleaned and entered into Microsoft Access or Excel, analysed, and managed in Stata 13 (StataCorp., USA). Descriptive data (frequencies and proportions) were conducted for the entire cohort and the participating respondents.
Not all data were available for every year, because the survey tool varied slightly as the programme progressed. The results presented below represent the data that could be directly correlated to demonstrate trends.

\section{Research ethics}

The protocol for the earlier surveys up to 2011 was approved by the University of KwaZulu-Natal, Durban, and subsequent surveys were approved by the University of Cape Town Human Research Ethics Committee (ref. no. HREC 450/2012). The survey was anonymous and the covering letter containing information about the study made it clear that completion of the questionnaire implied consent.

\section{Results}

\section{Turn-up and response rates}

The total study population each year varied between 1057 and 1308 . Turn-up rates were calculated independently of the surveys from data provided by the National Department of Health. Fig. 1 shows a slight decline in the year-on-year turn-up rate - from $91 \%$ in 2000 to $\sim 87 \%$ in 2013 , with an average of $89 \%$, although there were wide variations. The data were interrupted by the introduction of the 2-year internship in 2008.

Response rates to the survey varied from a high of $77 \%$ in 2001 to a low of $20 \%$ in 2002 , with an average of $51 \%$, as data collection methods and availability of funding changed. For 2001, 2009, 2011 and 2013, which were used for comparative analysis below, the number of respondents was 902 (77\%), 628 (48\%), 668 (55\%) and 648 (68\%), respectively. Response rates for doctors from different universities were very similar across all years, whereas response rates within different provinces varied between $15 \%$ and $73 \%$ from 2000 to 2009, and between $42 \%$ and 51\% from 2010 to 2014 .

\section{Demographics and allocations}

Of the total sample, 58\% were female and 36\% were married. While the proportion of respondents who stated coloured and Indian as race remained fairly constant, the proportion stating black as race increased from $17 \%$ in 2001 to $45 \%$ in 2012, and those stating white as race decreased from $50 \%$ to $33 \%$ over the same period. These reciprocal changes were particularly rapid in the period $2009-2012$.

There was a steadily increasing trend in the proportion of respondents who received a provincial study bursary - from $22 \%$ in 2009 to $42 \%$ in 2014 (no data were available before 2009). Similarly,

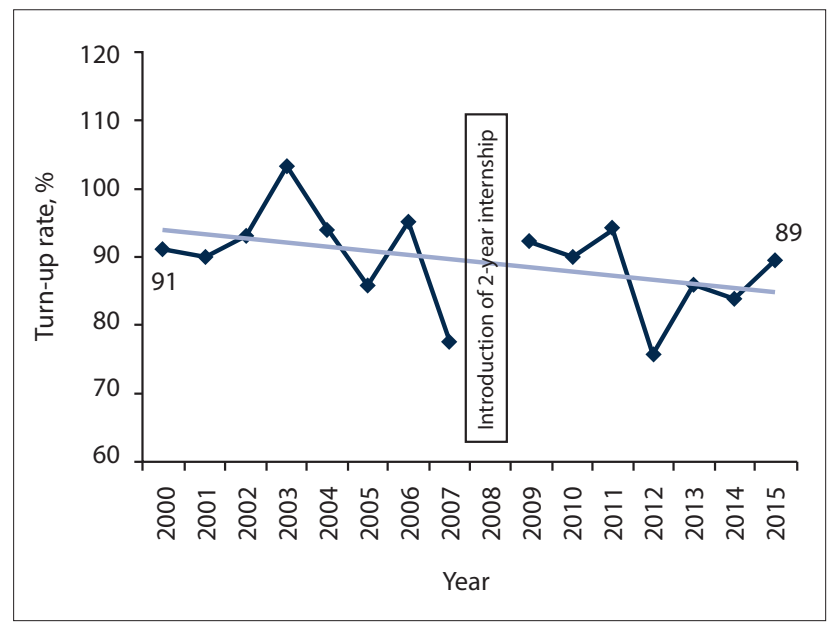

Fig. 1. Turn-up rates by doctors for community service from internship (by year). 
the proportion of those allocated to rural hospitals, as measured by the payment of the rural allowance, rose from $24 \%$ in 1999 , stabilising at $~ 50 \%$ between 2012 and 2014, with a high of $60 \%$ in 2007. The majority of CS respondents were placed at district hospitals, showing an increasing trend from $41 \%$ in 2001 to $49 \%$ in 2013 , while those placed at tertiary and specialised hospitals decreased over the same period - from $18 \%$ to $15 \%$ - and regional hospital placements also decreased from $33 \%$ to $22 \%$.

Fig. 2 plots the number of CS doctors allocated and the number of accredited facilities in each province against the percentage of the national population and the percentage of each rural provincial population, using data from StatsSA censuses 2001 and 2011, ${ }^{[20]}$ with the latter in decreasing order. The aim of this comparison was to show allocations in terms of relative need in rural areas. Limpopo Province received a disproportionately low number of CS doctors for its rural needs, while the Western Cape and Gauteng provinces received disproportionately high numbers of CS doctors.

Applicants to the programme were required to make five choices from a list of public healthcare facilities approved for CS by the National Department of Health. If an allocation was not made within these initial requests, a second round of five choices was made available. A third round followed for the few who were still not allocated in the second round. The results show that an average of $80 \%$ of applicants were placed in the first round; this remained fairly constant from 2001 onwards, with a range of $77-87 \%$. An average of $70 \%$ of respondents were satisfied with the allocation process. On analysing the proportion of posts filled by the end of the second

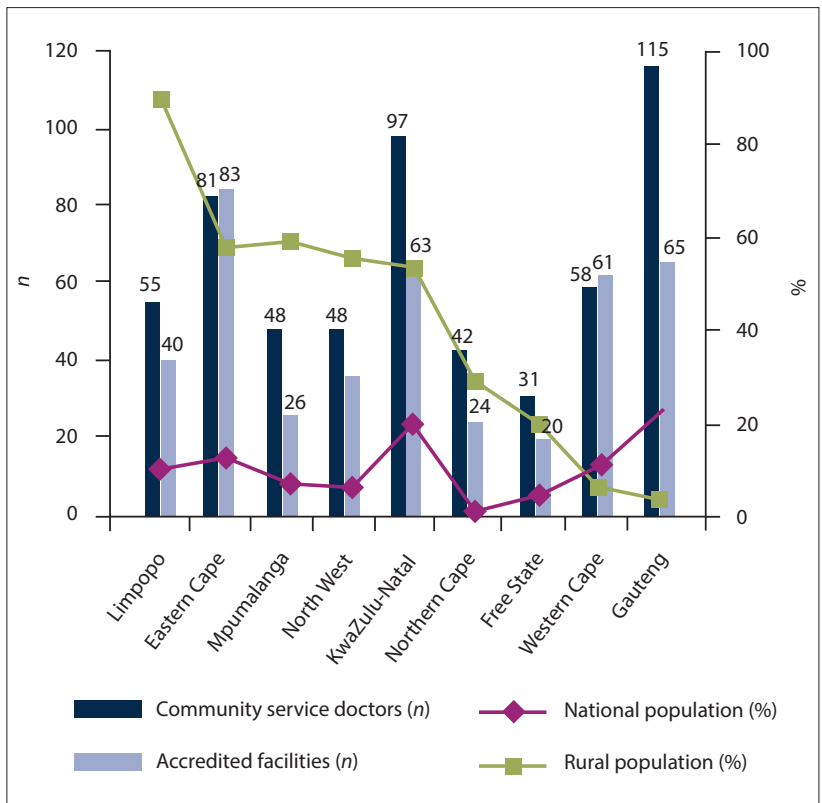

Fig. 2. Provincial rural population (\%), in decreasing order, and national population (\%) compared with community service doctors (n) and facilities accredited for community service (n) (by province). ${ }^{[20]}$ round, the rural provinces (Eastern Cape, Limpopo, Northern Cape and North West) had disproportionately high numbers of vacant CS posts, indicating that these were not popular choices. Turn-up rates in the third round of allocations were the lowest of all ( $\mathrm{H}$ Groenewald - personal communication, 2013).

\section{Experiences of community service}

A significant majority of respondents consistently stated that they had made a difference during their year of CS $(76 \%$ in 2001, rising to $91 \%$ in 2014), and that they had experienced professional development (range 72 -91\%). An average of $96 \%$ performed overtime duties. Of those provided with accommodation, an average of $61 \%$ were satisfied with it, but $64 \%$ felt some risk to their personal safety (Table 3).

A majority of CS doctors felt well orientated in their jobs (average 65\%) and thought that they received good clinical supervision (average 52\%). The latter varied according to placement site, with significantly fewer respondents in rural sites reporting good supervision than those in urban sites. However, just $<50 \%$ of respondents said that their managers handled their concerns well and they were satisfied with the support received from them. This varied significantly by province - from $39 \%$ in North West to $69 \%$ in Mpumalanga (Fig. 3).

The attitude towards CS has been increasingly perceived as positive overall from 1999 to 2013 (Fig. 4). In response to the statement: 'My attitude towards community service has become more negative/ positive as a result of my experience this year', the majority of respondents had shifted from a neutral attitude to a positive one over the course of the 15 years.

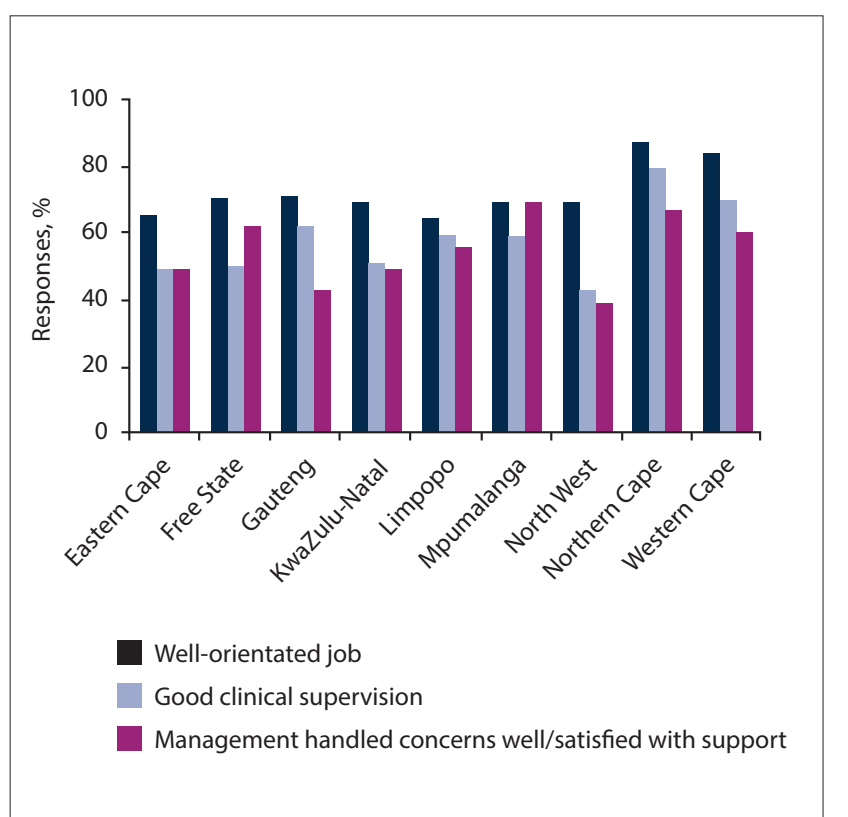

Fig. 3. Satisfaction of community service doctors with regard to supervision and support, 2001 -2014, as a percentage of responses (by province).

Table 3. Experiences of community service in $2001-2014$ in response to selected questions

\begin{tabular}{lllllll}
\hline Experiences & $\mathbf{2 0 0 1}$ & $\mathbf{2 0 0 9}$ & $\mathbf{2 0 1 2}$ & $\mathbf{2 0 1 3}$ & $\mathbf{2 0 1 4}$ & Average since 2009 \\
\hline Contributed to health of community/made a difference, \% & 76 & 84 & 96 & 94 & 91 & 91 \\
Experienced professional development, \% & 91 & 72 & 89 & - & 81 & 81 \\
Performed overtime duties, \% & 94 & 94 & 95 & 97 & 96 & 96 \\
Satisfied with accommodation, \% & 53 & 44 & 70 & 66 & 62 & 61 \\
No risk to personal safety, \% & 45 & 33 & 45 & 36 & 31 & 36
\end{tabular}


Table 4. Future career plans of 2001 - 2014 community service doctors

\begin{tabular}{lllllll}
\hline Future career plans & $\mathbf{2 0 0 1}$ & $\mathbf{2 0 0 9}$ & $\mathbf{2 0 1 2}$ & $\mathbf{2 0 1 3}$ & $\mathbf{2 0 1 4}$ & Average since 2009 \\
\hline Move overseas, \% & 43 & 7 & 2 & 0 & 5 & 4 \\
Private sector South Africa, \% & 7 & 16 & 27 & 4 & 8 & 14 \\
Specialise, \% & 34 & 64 & 34 & 38 & 62 & 50 \\
Stay at same facility, \% & - & 30 & 19 & 31 & 36 \\
Work in rural, underserved communities, \% & 19 & 22 & 27 & 11 & 2
\end{tabular}

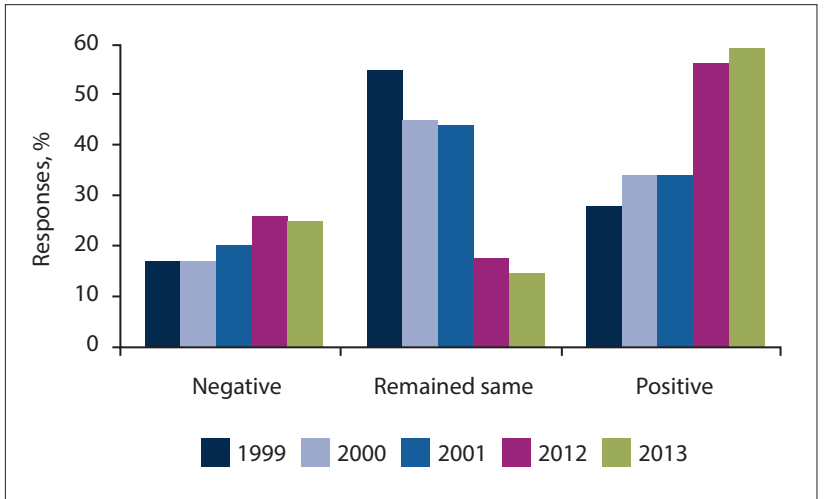

Fig. 4. Responses (\%) to the statement: 'My attitude towards community service has become more negative/positive because of my experience this year' (by year).

\section{Future career plans}

Future work intentions varied widely on an annual basis. When comparing the average of respondents for each career intention for the last 3 years, the intention to move overseas had decreased significantly since a record figure of $43 \%$ was obtained from the 2001 survey (Table 4). However, the intention to move into the private sector and specialise had increased somewhat, with an average of 50\% of CS doctors planning to specialise immediately after completing their CS year. The intention to remain at the same health facility and to work in rural, underserved communities had remained relatively static at $\sim 30 \%$ and $\sim 15 \%$, respectively.

\section{Discussion}

CS in SA has become institutionalised and has stabilised as a programme. In contrast to the first few years of uncertainty and resentment, the expectations of all current SA health science graduates are that they will undergo their CS year in a public hospital, which is likely to be in a rural area, and conversely, hospital managers have come to rely on them as human resources.

Studies in other low- and middle-income countries, including Puerto Rico, ${ }^{[21]}$ Indonesia, ${ }^{[22]}$ Turkey, ${ }^{[23]}$ and Thailand, ${ }^{[24]}$ have demonstrated an improvement of staffing levels by doctors after the introduction of a period of compulsory service. As Frehywot et al. ${ }^{[9]}$ assert:

'Compulsory service programmes are an instrument of social justice, an exercise in health equity, in that they enable governments to direct or augment health services to geographical areas that are not well served and in communities that are not favoured by market forces and health worker preferences.'

The increase in provincial study bursaries indicates an increasing sense of ownership of the future workforce by provincial health departments, and the allocation rate of $80 \%$ in the first round is commendable. However, if the turn-up rate is an indicator of the acceptability of CS among those who are eligible, the $11 \%$ who do not take up CS annually is cause for concern, as these 120 - 150 young doctors represent the output of one entire medical school. It is clear that there are significant personal choices to be made at that stage in life, such as starting a family or taking a break, and a degree of flexibility is needed. A small percentage might quit the profession either temporarily or permanently, and another group might head abroad directly after internship. Some applicants who are allocated in the second or third rounds might adopt a 'wait and see' strategy and do not turn up, preferring to wait unemployed for more desirable posts to become available in urban areas.

The primary objective of CS, to improve the distribution of health professionals throughout the country, has been partially achieved, as rural placements have increased to $\sim 50 \%$, but not to the extent of the relative need in rural provinces. Clearly, the CS workforce is a reliable recruitment strategy, bringing 8000 fresh young graduates into the public service each year to fill the posts vacated by their predecessors, but the temporary contract nature of these posts creates a situation of constant staff turnover and does little to create a stable long-term workforce. Other human resource mechanisms complementary to CS are needed to achieve this. In other words, CS is an effective recruitment strategy, but in the absence of other interventions, does nothing for the development of an effective long-term workforce. Few international studies have shown increased retention of doctors after compulsory CS, while one SA study found $16 \%$ of CS doctors in one province remaining at the same district hospital beyond the obligatory time ${ }^{[14]}$ Pathman et al. ${ }^{[25]}$ in a 9-year follow-up study of doctors in the National Health Corps in the USA, found that those who were contracted into service in rural areas as compensation for the payment of their education costs, did not remain longer than their required service obligations. As previously pointed out, CS might to some extent defeat its own ends if newly qualified professionals assume that they have 'done their duty' and have compensated society for the costs of their studies after only 1 year in public service. ${ }^{[2]}$ Nonetheless, the Umthombo Youth Development Foundation has raised the retention of graduates from rural areas that they support to $>70 \%$ after they have completed their year-for-year contract time by means of effective mentoring and support. ${ }^{[26]}$ It is, therefore, possible to achieve a much higher rate of retention in SA through complementary strategies.

Considering the data on career plans of CS doctors, the consistent $30 \%$ who preferred to stay on at their CS placement site, and the $15 \%$ who were prepared to work in rural or underserved areas after CS, consistent with other studies, represented an important human resource. If the latter were to be permanently employed and incentivised to create a longer-term experienced workforce, the problem of retention of professional staff in rural and remote areas could be solved in a few years by the accumulation of successive cohorts of willing professionals. It is better to have 1 doctor for 10 years than 10 doctors for 1 year each, as the continuity of relationships in medicine is not only more efficient but also leads to greater job satisfaction. In terms of achieving the first objective of CS, this hypothetical approach could be contrasted with forcing all graduates to work as so-called 'slaves of the state. ${ }^{[27]}$ However, despite 
Table 5. Recommendations from the Community Service for Health Professionals summit held at the Foundation for Professional Development, 2015 ${ }^{[19]}$

\begin{tabular}{|c|c|c|}
\hline Policy & Partnerships & Research \\
\hline $\begin{array}{l}\text { A facility accreditation system for facilities } \\
\text { designated for CS should be developed and } \\
\text { implemented }\end{array}$ & $\begin{array}{l}\text { Developing quality accommodation potentially } \\
\text { through PPPs should be investigated, accessing } \\
\text { CSI funding sources } \\
\text { Consider models where government provides } \\
\text { land, financial guarantees and rentals }\end{array}$ & $\begin{array}{l}\text { CS research must be driven by the } \\
\text { human resource needs of the country } \\
\text { and each province, district and facility, } \\
\text { as determined by the HRH strategy and } \\
\text { workload indicators of staffing need }\end{array}$ \\
\hline $\begin{array}{l}\text { Create incentives to improve the experience } \\
\text { of CS officers during rural placements; could } \\
\text { include supported professional development } \\
\text { opportunities, study leave and job security }\end{array}$ & $\begin{array}{l}\text { Sponsorship for CS officers to attend national } \\
\text { conferences would reduce their personal isolation } \\
\text { during CS and provide them with professional } \\
\text { development }\end{array}$ & $\begin{array}{l}\text { Research into the CS programme must } \\
\text { be framed in terms of the national HRH } \\
\text { strategy, and should both strengthen and } \\
\text { be supported by it }\end{array}$ \\
\hline
\end{tabular}
through multi-year employment contracts beyond CS year

It should clearly articulate a strict focus on underserved areas (rural and urban), where CS officers are enabled to meet community needs

There should be clear policy and transparent standardised guidelines on the allocation of CS posts

Requests for alternative placements should not compromise the policy objectives, particularly placement in rural, underserved areas, and a system to monitor abuse should be established Full-time positions in the public sector should be marketed to CS officers

Finding a mechanism through which to link CS-hosting hospitals with Wi-Fi, would improve access to training via online portals, as well as allow professional support and training via telemedicine and video conferencing Local senior professionals should be approached for support, including district clinical specialist teams

The role of communities around rural and underserved facilities should be defined and promoted, including community awareness of the services and involvement in providing support Community members should be included in orientation programmes Training and support partners should be engaged to design and implement orientation for CS professionals (cultural, logistical and clinical) based on existing programmes
More peripheral sites should be accredited for academic rotations to ensure increased access to senior professionals for clinical support and exposure to specialties
Qualitative information regarding CS should be collected and analysed on an ongoing basis

This is one form of giving the participants a voice

Budgeting for posts, the costeffectiveness of CS, and the follow-up of provincial bursary holders are important issues that affect the implementation of CS

Cost-effectiveness and efficiency studies should be undertaken

$\mathrm{CS}=$ community service; $\mathrm{CSI}=$ corporate social investment; $\mathrm{HRH}=$ Human Resources for Health; $\mathrm{PPP}=$ public-private partnership.

the significance of the reaction to the coercive nature of CS, it has stabilised over time, as the turn-up rate of almost $90 \%$ and the rural career plans of $15 \%$ of each cohort mentioned above indicate.

The year-on-year variability of career plans is difficult to explain logically, apart from fluctuations in collective aspirations as opportunities changed. Since 2001, the decrease in intentions to practise abroad has been substantial, and probably is the result of the tightening of registration requirements in other countries rather than reduced local 'push' factors. ${ }^{[28]}$ There may also have been a response bias, as those who were considering leaving the country may have been reluctant to reveal their plans in the survey, despite assurances of anonymity. The $30 \%$ who preferred to stay on at their CS hospital were probably disappointed because of the fixed-term contracts, as noted above, and the increasing challenge that provincial health departments are now having in funding permanent posts with the current budgetary restrictions.

The second objective of CS is also important, i.e. the professional development of young professionals. Often CS is the first in-depth exposure that junior doctors have to rural or underserved communities, and it is a significant wake-up call to the real health needs of large numbers of South Africans. Having the skills and confidence to make a difference after the 2-year internship, allows young doctors to stand on their own feet professionally and fulfil a real need, which carries the sense of professional satisfaction seen in the results. The direct exposure to the consequences of resource constraints in the public health service, including a relative lack of supervision and support, while not ideal, nevertheless serves to develop resilience in our young professionals for the challenges of future practice. By comparison, those trained in well-resourced settings do not cope as well. ${ }^{[29]}$

Attitudes towards CS have become progressively more positive over 15 years, rated by successive cohorts of CS doctors, which is an interesting finding, as it indicates that the experience of CS has shifted significantly, and the uncertainty and resentment that surrounded CS in its early years have possibly given way to accepting it as an unavoidable part of career development. The introduction of the occupation-specific dispensation in $2007,{ }^{[30]}$ which raised doctors' salaries to relatively high levels, might be linked to the improvement in attitudes, while more indirect links could have been the parallel increase in the proportion of black graduates, provincial bursary holders and rural placements. More qualitative research is warranted to explore this phenomenon.

The level of support from managers, rated at an average of $50 \%$, is inadequate and represents a waste of human resource potential. That 
$<50 \%$ of the respondents in KwaZulu-Natal, Limpopo and Mpumalanga felt adequately supervised clinically and supported by management, is an indictment on those seniors and managers. This young cohort of professionals could contribute their skills and energy far more effectively if they are proactively incorporated into working teams, supervised and mentored by more experienced practitioners, and supported administratively through decent housing and living conditions.

\section{Study limitations}

The response rates were reasonable for repeated surveys of this nature, but the limitations of the study include a substantial response bias. Those who completed the surveys, although demographically similar to the study population as a whole, were more likely to have been positive about their experiences; therefore, the results may reflect a more optimistic view than the reality. They also rely on selfreported feedback, which cannot easily be verified, and so the true picture of CS may be different to what is reported. The changes in the survey tool over 15 years introduced some variations, but having a single principal investigator played a part in ensuring consistency of data collection and results. Finally, a possible social desirability bias was mitigated to some extent by emphasising that the results would be collated by an organisation independent of the National Department of Health - in earlier surveys the University of KwaZuluNatal and in later ones, Africa Health Placements.

\section{Conclusion}

This study is the first to track the experience of compulsory CS over time in any country in order to describe the trends once CS has become institutionalised. The SA experience of CS for doctors over the first 15 years appears to have been a successively positive one, and it has largely met its original objectives of redistribution and professional development. CS has become an indispensable part of the provincial health services, particularly in rural hospitals, but also in larger urban hospitals. It is a medical workforce that managers can rely on each year without having to actively recruit, at the cost of annual orientation and management of successive cohorts of young professionals. As the results show, however, they could improve this renewable resource by giving more attention to orientation, management support and clinical supervision, and by focusing professional development opportunities on the important minority who are prepared to stay on longer than their obligatory year. As an entrenched feature of the national HRH strategy, CS still needs to be complemented by other interventions to capitalise on the potential it represents. Alternative strategies to retain doctors and other health professionals in rural and underserved areas, as suggested by the WHO, must be considered rather than relying only on coerced junior health professionals who rotate out after a year. A stable long-term workforce can only be achieved, particularly in rural and underserved areas, through a multifaceted human resource management plan.

\section{Recommendations}

Recommendations from the Community Service for Health Professionals summit, held at the FPD, are set out in Table 5. ${ }^{[19]}$

Acknowledgements. The authors are grateful to the National Department of Health, provincial CS co-ordinators and hospital CS co-ordinators for their assistance with data collection, and Alet Bosman of the Foundation for Professional Development (FPD) for assisting with data analysis. We thank the FPD and Dr Gwen Ramokgopa for convening the 2015 summit.
Author contributions. SR: designed the study, oversaw the data collection and drafted the manuscript as a whole. JP: collated the data, performed the statistical analyses and drafted the methods and findings sections. SK: facilitated the data collection from 2011 and reviewed the manuscript. GW: facilitated the funding for the study from 2011, and reviewed the manuscript.

Funding. The initial study was funded by the Health Systems Trust, and annual surveys from 2000 to 2010 were funded by the National Department of Health. Surveys from 2011 to 2014 were funded by the United States Agency for International Development (USAID) under the United States President's Emergency Plan for AIDS Relief (PEPFAR) programme.

Conflicts of interest. None. 1. Motsoaledi A. Community service to improve access to quality health care to all South Africans.
Budget Speech. 2014. http://www.doh.gov.za/show.php?id=447 (accessed 24 November 2017).

Budget Speech. 2014. http: //www.doh.gov.za//how.php?id=447 (accessed 24 November 2017).
. Reid S. Community Service for Health Professionals. South African Health Review. Durban: Health 2. Reid S. Community Service
Systems Trust, 2002:135-160.

Reid SJ. Compulsory community service for doctors in South Africa - an evaluation of the first year. S Afr Med J 2001;91(4):329-336.

4. National Department of Health. Health Professions Act 56, 1974. Regulations relating to performance of community service by persons registering in terms of the Health Professions Act, 1974. Government Gazette No. 18890:R688. 1998.

5. Naidoo S, Chikte U. Community dental service - the first year. S Afr Dent J 2002;57(5):193-196.

6. Khan NB, Knight S, Esterhuizen T. Perceptions of and attitudes to the compulsory community service programme for therapists in KwaZulu-Natal. S Afr J Comm Disord 2009;56:17-22.

Visser J, Marais M, Plessis J, Steenkamp I, Troskie I. Experiences and attitudes of dietitians during the first compulsory community service year. S Afr J Clin Nutr 2006;19(1):10-17. https://doi.org/10.1080 first compulsory community se
$\% 2 \mathrm{~F} 16070658.2006 .11734084$

8. Pillay A, Harvey B. The experiences of the first South African community service clinical psychologists. S Afr J Psychol 2006;36:259-280. https://doi.org/10.1177\%2F008124630603600204

9. Frehywot S, Mullan F, Payne PW, Ross H. Compulsory service programmes for recruiting health Frehywot S, Mullan F, Payne PW, Ross H. Compulsory service programmes for recruiting health
workers in remote and rural areas: Do they work? Bull World Health Organ 2010;88:364-370. https:// doi.org/10.2471\%2Fblt.09.071605

10. World Health Organization. Increasing Access to Health Workers in Remote and Rural Areas Through Improved Retention: Global Policy Recommendations. Geneva: WHO, 2010.

11. Dolea C, Stormont L, Braichet J-M. Evaluated strategies to increase attraction and retention of health workers in remote and rural areas. Bull World Health Organ 2010;88(5):379-385. https://doi org/10.2471\%2Fblt.09.070607

12. Nemutandani MS, Maluleke FRS, Rudolph MJ. Community service doctors in Limpopo province. S Afr Med J 2006;96(3):180-182.

13. Penn C, Mupawose A, Stein J. From pillars to posts; some reflections on community service six years on. S Afr J Commun Disord 2009;56:8-16.

14. Ross A, Reid S. The retention of community service officers for an additional year at district hospitals in KwaZulu-Natal and the Eastern Cape and Limpopo provinces. S Afr Fam Pract 2009;51:249-253. in KwaZulu-Natal and the Eastern Cape and Limpopo
https://doi.org/10.1080\%2F20786204.2009.10873856

15. Parker W, Steyn N, Mchiza Z, et al. Challenges for efficient health service delivery: Experiences of Parker W, Steyn N, Mchiza Z, et al. Challenges for efficient health service delivery: Experiences of
dietitians completing their compulsory community service year in South Africa. Public Health Nutr dietitians completing their compulsory community service year in Sou
2012;15(8):1411-1418. https://doi.org/10.1017\%2Fs1368980011003314

16. Van Niekerk J de V. Internship and community service require revision. S Afr Med J 2012;102(8):638. https://doi.org/10.7196\%2Fsamj.6094

17. Hatcher AM, Onah M, Kornik S, Peacocke J, Reid S. Placement, support, and retention of health professionals: National, cross-sectional findings from medical and dental community service officers in South Africa. Hum Resour Health 2014;12:14. https://doi.org/10.1186\%2F1478-4491-12-14

18. National Department of Health. Human Resources for Health Strategy for the Health Sector 2012/13 - 2016/17. Pretoria: NDoH, 2011.

19. Foundation for Professional Development. Report of the Community Service for Health Professionals Summit, 22 April 2015. Pretoria: FPD, 2015.

20. Laldaparsad S. Urban and rural trends in South Africa. Pretoria: Statistics South Africa, 2012

21. Ramírez de Arellano AB. A health 'draft': Compulsory health service in Puerto Rico. J Public Health Policy 1981;2:70-74. https://doi.org/10.2307\%2F3342100

22. Lehmann U, Dieleman M, Martineau T. Staffing remote rural areas in middle- and low-income Lehmann U, Dieleman M, Martineau T. Staffing remote rural areas in middle- and low-income
countries: A literature review of attraction and retention. BMC Health Serv Res 2008;8:19. https://doi. org/10.1186\%2F1472-6963-8-19

23. Erus B, Bilir A. Obligatory service requirement and physician distribution in Turkey. Eur J Public Health 2007;17(Suppl 2):175

24. Wongwatcharapaiboon P, Sirikanokwilai N, Pengpaiboon P. The 1997 massive resignation of contracted new medical graduates from the Thai Ministry of Public Health: What reasons behind? Hum Res Health Develop J 1999;3:147-156.

25. Pathman DE, Konrad TR, Ricketts TC. The comparative retention of National Health Service Corps and other rural physicians; results of a 9-year follow-up study. JAMA 1992;268(12):1552-1558. https:// doi.org/10.1001\%2Fjama. 1992.03490120066030

26. Ross A, MacGregor G, Campbell L. Review of the Umthombo Youth Development Foundation scholarship scheme, 1999 - 2013. Afr J Prim Health Care Fam Med 2015;7(1):1-6. https://doi. org/10.4102\%2Fphcfm.v7i1.739

27. Erasmus N. Slaves of the state: Medical internship and community service in South Africa. S Afr Med J 2012;102(8):655. https://doi.org/10.7196\%2Fsamj.5987

28. Labonté R, Sanders D, Mathole T, et al. Health worker migration from South Africa: Causes, consequences and policy responses. Hum Resource Health 2015;13:92. https://doi.org/10.1186/ s12960-015-0093-4

29. Phalime M. Postmortem: The Doctor Who Walked Away. Cape Town: Tafelberg, 2014

30. South Africa. Occupation Specific Dispensation (OSD) in the Public Service. 2007. 